\title{
La jornada de reconciliación nacional del 5 de mayo de 1958
}

\author{
FÉlIX HERNÁNDEZ \\ Doctorando. Dpto. H. ${ }^{a}$ Contemporánea. UNED/CIHDE \\ La jornada de reconciliación nacional del 5 de mayo de 1958
}

\begin{abstract}
RESUMEN
En la segunda mitad de la década de los cincuenta la dictadura franquista atravesaba un período de crisis, ante la gravedad de la situación socio-económica que atravesaba el país, es en este contexto en el que el Partido Comunista de España decidió convocar una jornada de movilización contra la dictadura, a la que denominó Jornada de Reconciliación

Nacional, para el 5 de mayo de 1958, pese a estar precedida de un período de fuertes protestas sociales los resultados de la misma fueron muy modestos, en este hecho influyeron el propio aislamiento en que se encontraban los comunistas dentro de la oposición antifranquista, como el miedo a la represión, mientras el franquismo continuaría recibiendo el apoyo de las instituciones políticas y grupos sociales sobre las que se asentaba asi como sus apoyos exteriores, lo que le permitiría imponer sus propias soluciones $y$ sobrevivir hasta la muerte del dictador.
\end{abstract}

PALABRAS CLAVE Franquismo, PCE, huelgas, Reconciliación Nacional

\begin{abstract}
In the second half of the fifties, the Franco dictatorship was going through a period of crisis given the gravity of the socioeconomic situation that the country was facing. It is in this context that the Spanish Communist Party decided to call mobilization day against dictatorship, which he called National Reconciliation Day, for the 5th of May 1958. Although it was preceded by a period of strong social protest, the results of it were very modest. In this event influenced the isolation itself in which the Communists were inside the anti-Franco opposition, as the fear of repression. While the Franco's regime would continue receiving the support of political institutions and social groups on which was laid down as well as their external supports, which would enable it to impose its own solutions and survive until the dictator's death
\end{abstract}

KEY WORDS

Francoism, PCE, strikes, Nacional Reconciliation 


\section{EL PROCESO HACIA LA JORNADA}

El día 5 de mayo de 1958 estaba convocada por el Partido Comunista de España una Jornada de Reconciliación Nacional contra la dictadura. Según Carrillo el origen de esta convocatoria se encontraba en el Pleno de la Reconciliación Nacional que el partido celebró a fines de julio y principios de agosto de $1956^{1}$; considero que este hecho debe ser matizado, la idea de colaboración con algunas fuerzas afines al franquismo para lograr la caída del régimen no era ni nueva ni exclusiva de este partido sino que fue ensayada por diversos grupos y en diversos momentos a lo largo del período franquista, incluso los mismos comunistas, durante la Segunda Guerra Mundial, había promovido la política de Unión Nacional con unos principios teóricos son muy similares a los de la Reconciliación Nacional. En marzo de 1956 Mundo Obrero, órgano de expresión del PCE, publicó un manifiesto del Comité Central del partido, elaborado el mes anterior, en el que estaban reflejadas las ideas fundamentales de la jornada: la huelga general, la necesidad de unión de los trabajadores de todas las tendencias, y su predisposición a colaborar con otros grupos, como los católicos, e incluso con ciertos elementos del Sindicato Vertica?.

En el mes de abril de ese año se produjo una oleada de huelgas y protestas obreras, la más importante de las que hasta ese momento había sufrido el régimen, sus principales focos fueron Navarra, Barcelona, Guipúzcoa y Vizcaya; esta movilización no puedo ser contenida únicamente con métodos represivos y las autoridades se vieron obligadas a conceder un incremento salarial que supuso la recuperación del nivel de salarios reales de 1936; al desencadenamiento de estas movilizaciones, junto al malestar obrero por sus condiciones de vida y trabajo, contribuyo la actitud de una nueva generación obrera formada al margen de las tradiciones sindicales anteriores a la guerra, pero también sin los traumas de la guerra y la posguerra y más fácilmente dispuesta a romper el silencio y la pasividad. Para evitar la reproducción de las mismas el $1 .^{\circ}$ de Mayo fue declarado fiesta oficial, en esta ocasión el PCE manifestaba haber llamado a los trabajadores a celebrar este día bajo el signo de la Reconciliación Nacional ${ }^{3}$. Otros hechos que se produciría este año y que quizás harían pensar a los comunistas que se encontraban en el camino correcto serían el abandono de régimen por parte de algunos intelectuales falangistas, como Ridruejo, Lain Entralgo y Tovar, o el enfrentamiento de Franco con el Capitán General de Cataluña cuando este se negó a sacar a las tropas a la calle para combatir el movimiento huelguístico.

En este marco tuvo lugar el ya citado Pleno del Comité Central, sin embargo el manifiesto que elaboró, según lo refleja Mundo Obrero, es un texto de contenido político en el que no se menciona la idea de la Jornada de Reconciliación Nacional4

\footnotetext{
1 CARRILLO, S.: Memorias. Barcelona, Editorial Planeta, S.A., 1993, p.455.

Mundo Obrero, marzo de 1956.

3 Mundo Obrero, mayo-junio de 1956.

4 Mundo Obrero, agosto-septiembre de 1956.
} 
A lo largo de 1957 se mantendría un clima de conflictividad latente, el año comenzaría con un nuevo boicot a los tranvías en Barcelona, que pese a su amplio seguimiento no consiguió sus objetivos, ante la firmeza de las autoridades franquistas, en el mes de marzo, como continuación de algunas acciones anteriores entre las que destaca la ocurrida en La Camocha, se produjo un importante conflicto en la minería asturiana que afectó a miles de mineros, lo que suponía la reincorporación de estos trabajadores a las posiciones de vanguardia dentro del movimiento obrero que habían ocupado con anterioridad a la Guerra Civil, también en Madrid se produjo un boicot a los transportes y en diversas empresas del País Vasco se produjeron algunos conflictos importantes. La crisis del régimen parecía evidente, y el franquismo trató de darle respuesta mediante el cambio de gobierno que se produjo en el mes de febrero de ese año con la entrada de una serie de ministros tecnócratas, vinculados al Opus Dei, lo que sería el punto de arranque del gran viraje de la política económica del régimen hacia la liberalización y hacia la integración en la economía internacional ${ }^{5}$.

En el mes de septiembre Mundo Obrero $0^{6}$ dedicó su número casi íntegramente a la resolución del Comité Central que suponía el primer planteamiento de la jornada, los objetivos de la misma eran «contra la carestía de la vida y la política económica de la dictadura, por la amnistía para los presos y exiliados políticos, por las libertades políticas», en esta resolución se afirmaba:

Los comunistas no concebimos la JORNADA DE RECONCILIACIÓN NACIONAL como un movimiento subversivo, como la consecuencia de una conspiración, ni como un choque violento contra la dictadura. Tampoco la consideramos como el último acto contra la dictadura, aunque al producirse aceleraría la liquidación de ésta.

También se afirmaba en el mismo que se concebía la jornada como la coincidencia con católicos, monárquicos, liberales, nacionalistas, cenetistas e incluso se mostraba partidario de que participaran en la misma grupos falangistas, si lo deseaban y estaban de acuerdo con el carácter de la convocatoria.

En las instrucciones sobre las acciones a llevar a cabo a la clase obrera y las masas trabajadoras de la ciudad y el campo, se las llamaba a la clase obrera a participar «Según las condiciones locales concretas», de algunas formas que podrían ir desde:

concentraciones en los sindicatos reclamando sus reivindicaciones hasta la huelga, pasando por la huelga de brazos caídos dentro de las fábricas, todo el día o parte de la jornada, según las posibilidades, y cuantas formas aparezcan como las más oportunas en cada lugar.

${ }^{5}$ MOLINERO, C. e YSÀS, P.: Productores disciplinados y minorías subversivas. Clase obrera y conflictividad laboral en la España franquista. Madrid, Siglo XXI de España Editores, S.A., 1998, p.41.

6 Mundo Obrero, septiembre de 1957. 
En el caso de la población campesina se les proponía como «una forma asequible» el recogimiento en sus casas durante todo o parte del día y el cierre de los establecimientos públicos.

Esta decisión del PCE preocupó a los medios oficiales y aparatos de represión, y en el mes de enero de 1958 se anunciaba la detención de Javier Pradera y 44 personas más en Madrid, Zaragoza y Valencia; en el lenguaje oficial era «una tentativa de reconstrucción del Partido Comunista y de reanudar sus actividades en España...» refiriéndose a «una pretendida jornada de reconciliación nacional (que) debería consistir en una subversión general del orden público normal»»7.

En los primeros meses del año, en Asturias se inició una nueva ola de conflictos, posteriormente extendida al País Vasco y a Cataluña, la huelga de $20000 \mathrm{mi}$ neros de las cuencas del Nalón, del Caudal y de Gijón provocó una reacción gubernamental de extrema dureza, que llegó a la suspensión de algunos artículos del Fuero de los Españoles. También en Cataluña, la huelga de las grandes empresas de Barcelona en el mes de marzo desencadenó una durísima represión, con la detención de varios centenares de trabajadores y con un grupo de militantes comunistas sometidos a un consejo de guerra ${ }^{8}$

Estos conflictos llevaron a los dirigentes comunistas a considerar que la situación era propicia para la acción, y así Mundo Obrero en un artículo firmado por Mije veía en la huelga de la minería asturiana como el "arranque de la jornada ${ }^{9}$ y se empezaba a concretar su fecha en abril o mayo.

En el siguiente número de este periódico se publicaba un llamamiento titulado «EL PARTIDO COMUNISTA SE DIRIGE A TODAS LAS FUERZAS POLÍTICAS DEL PAÍS", en el se afirmaba, entre otras cosas:

El Partido Comunista declara nuevamente en esta ocasión, ante la clase obrera en lucha, ante todos los españoles, su disposición a llegar a un acuerdo con el Partido Socialista, la C.N.T., los Partidos republicanos, la democracia cristiana y otros grupos católicos, los sectores de la oposición liberal, los accidentalistas monárquicos y militares, e incluso con grupos disidentes de la Falange, para poner fin por medios pacíficos al régimen de dictadura y restablecer los derechos democráticos de los españoles, sin venganzas ni represalias ${ }^{10}$.

Por fin el siguiente número de Mundo Obrero, fechado el 30 de abril, fijaba el día 5 de mayo para la celebración de la jornada, y en el, además de a los obreros, se hacían llamamientos a intelectuales, comerciantes e industriales, estudiantes, gentes del campo, militares y fuerzas del orden público para que participaran en la

7 BIESCAS, J. A. y TUÑÓN DE LARA, M.: España bajo la dictadura franquista (1939-1975). Tomo X de la Historia de España dirigida por Manuel Tuñón de Lara. Barcelona, Editorial labor, S.A., 1980, p.323

8 MOLINERO, C. e Ysàs, P. op. cit. p.41.

9 ADELANTE EN LA ORGANIZACIÓN DE LA JORNADA, Mundo Obrero. 31 de marzo de 1958.

10 Mundo Obrero, 15 de abril de 1958. 
misma, este número terminaba con un MANIFIESTO DEL PARTIDO COMUNISTA DE ESPAÑA EN EL PRIMERO DE MAYO instando a participar en la misma ${ }^{11}$.

Mientras los medios gubernamentales no permanecían indiferentes, si al principio del bienio de protestas, en 1956, habían tratado de desactivar las luchas obreras con concesiones económicas, después se decidieron por un aumento de la acción represiva, una ley del 22 de marzo de 1957 permitía que en actividades colectivas ilegales, como las huelgas, en que no se pudiera identificar a los responsables, se detuviera a aquéllos con puestos de responsabilidad o de mayor veteranía entre los involucrados. El 24 de enero de 1958 se estableció un nuevo tribunal militar con jurisdicción en todo el país sobre actividades extremistas, bajo la dirección del coronel Enrique Eymar que adquirió una fama siniestra en la siguiente década ${ }^{12}$. Y con ocasión de la jornada la represión fue usada de manera importante, en el caso de Madrid Babiano habla de una «represión de carácter profiláctico" que traería importantes repercusiones sobre el Partido en la capital de España ${ }^{13} ;$ y diversas fuentes hablan de un extraordinario despliegue de las fuerzas policiales en los días anteriores a la jornada, extrañamente el desfile de la victoria no se había celebrado el $1 .^{\circ}$ de abril como correspondía, sino que casualmente se celebraría el domingo 4 de mayo, vísperas de la jornada ${ }^{14}$.

También se tomaron otras medidas de carácter más discreto, según David Ginard el Gobierno Civil de las Baleares, seguramente siguiendo un modelo remitido por las autoridades centrales, elaboró una serie de medidas preventivas, que incluían ante un posible boicot a la compra de periódicos los elementos de orden, funcionarios públicos y miembros de Partido debían de adquirir la Hoja del Lunes, la vigilancia en los transportes y mercados, la información sobre el rendimiento en el trabajo y el control del orden público sin alardes ni visibilidad que puedan producir alarma ${ }^{15}$. También va a darse una fuerte campaña de prensa, principalmente por parte de los diarios de carácter falangista, donde se hacía alusión a la Guerra Civil y mostrando fotografías relacionadas con sucesos como la Revolución de octubre de 1934, a la vez que se insistía en una supuesta reconciliación nacional que al parecer ya se había producido bajo el régimen franquista ${ }^{16}$.

11 Mundo Obrero, 30 de abril de 1958.

12 PAYNE, S., G.: El primer franquismo, 1939-1959. Los años de la autarquía. Historia de España N. ${ }^{\circ}$ 28. Madrid, Historia 16-Ediciones Temas de Hoy, 1997, p.132.

13 BABIANO, J.: «Madrid, primavera de 1962: el débil eco de Asturias» en R. Vega (coord.): El camino que marcaba Asturias. Las huelgas de 1962 en España y su repercusión internacional. Gijón, Ediciones Trea, S.L.-Fundación Juan Muñiz Zapico, 2002.p.304.

${ }^{14}$ No he encontrado en la prensa de la época ninguna explicación referente a este cambio de fechas; Mundo Obrero lo consideraría como «pretexto para el establecimiento del estado de guerra en todas las ciudades y villas de importancia» (Mundo Obrero, 15 de mayo de 1958).

15 GINARD I FÉRON, D.: «Expansión turística y conflictividad social: Las huelgas del 62 en las Islas Baleares» en R. Vega (coord.) op. cit. p.200.

16 Veasé, por ejemplo el diario Arriba del 3 de mayo de 1958. 


\section{RESPUESTA A LA CONVOCATORIA}

De diversas fuentes comunistas, tanto documentos internos como las informaciones de Mundo Obrero, así como los recuerdos de algunos militantes ${ }^{17}$, parece reflejarse que existía una cierta expectación, sin embargo los resultados no serían nada espectaculares.

En Madrid un informe redactado ese mismo día por el Delegado Provincial de Sindicatos ${ }^{18}$, de un lado considera el uso del transporte público ese día de "casi normal»", contradiciendo lo afirmado por algunos historiadores de hablan de un boicot efectivo de los transportes en los barrios populares de la capital ${ }^{19}$, dando como datos una retracción de un 20 a un $25 \%$ en Useras, Vallecas y Puente de Toledo, consideraba que el uso había sido casi normal en Cuatro Caminos y Ventas y casi normal en el Alto de la Carretera de Extremadura; Mundo Obrero habla de un boicot masivo, al mismo tiempo que denuncia que las autoridades habían movilizado a gran cantidad de gentes para que pasearan en tranvías a lo largo de todo el recorrido ${ }^{20}$, el hecho de las autoridades franquistas hubiesen utilizado ya esta táctica con motivo de la huelga blanca siete años antes, en unas circunstancias similares ${ }^{21}$, da una cierta credibilidad a esta afirmación.

Este mismo diario señala que la huelga había triunfado plenamente en la construcción donde consideraba que «la huelga — realizada de una forma o de otra- ha sido casi general». El Delegado del Sindicato Vertical aunque no admite este hecho si reconoce la existencia de numerosas acciones obreras en este sector. Al referirse una veintena de empresas aparece la expresión «solucionado» lo que parece referirse a aquellas cuyos trabajadores en algún momento se adhirieron a la protesta y posteriormente volvieron a la normalidad por si solos. En otras siete el informe destaca que el asunto se había solucionado con la intervención de diversos cargos sindicales (vocales, jerarcas del sindicato de la construcción etc.). En cinco la solución había llegado por la intervención de las fuerzas policiales, en algunos casos con la colaboración de componentes de la OSE, y tras la detención de varios trabajadores. En seis, o grupos de ellas, como en las Obras del Pozo del Tío Raimundo los obreros acudieron a trabajar y con posterioridad habían abandonado la obra. En varias no se había trabajado por la mañana. En al menos otras doce habían faltado al trabajo parte o la totalidad de la plantilla o se había hecho

\footnotetext{
17 Veasé lo afirmado por Monzón sobre Valencia en SANZ, Jesús: El movimiento obrero en el País Valenciano (1939-1976). Valencia, Fernando Torres Editor, 1976, p.59.

18 INFORME QUE ELEVA A LA CONSIDERACIÓN DE LAS AUTORIDADES SUPERIORES LA DELEGACIÓN PROVINCIAL DE SINDICATOS, DE ACUERDO CON LOS INFORMES RECIBIDOS DE LOS DISTINTOS SINDICATOS AFECTADOS POR LAS INCIDENCIAS OCURRIDAS EN EL DIA DE HOY, 5 de mayo de 1958; Archivo General de la Administración (AGA), Fondo Sindicatos, caja 4790.

19 BIESCAS, J. y TUÑÓN DE LARA, M. op. cit.p. 323.

20 Mundo Obrero, 15-31 de mayo de 1958.

21 Informe del Jefe Provincial del Movimiento de Madrid al Ministro Secretario General del Movimiento, 23 de mayo de 1951; AGA, Fondo: Presidencia-Secretaría General del Movimiento, Caja $51 / 19034$.
} 
huelga de brazos caídos; no obstante esta fuente admite que no ha contabilizado los paros realizados en un numeroso grupo de empresas que por su pequeño numero de obreros le parecen insignificantes.

En Barcelona Dora Palomero considera que la jornada apenas tuvo repercusión ${ }^{22}$; el informe que los militantes comunistas enviaron a la dirección se reconocía que la jornada en Barcelona ha sido un fracaso ${ }^{23}$, es de destacar el hecho de que Mundo Obrero, al contrario de lo que hará refiriéndose a los mas diversos lugares de la geografía española, no hable de boicot a los tranvías, práctica que había sido muy utilizada por los barcelonenses en anteriores protestas; según este diario la forma en que los obreros de la ciudad condal habrían participado habría sido el trabajo lento, que según el diario del PCE se había realizado de una forma muy extendida, no obstante el informe de los comunistas barcelonenses habla de diversas acciones el algunas poblaciones del área metropolitana de la ciudad como Sabadell, donde se habían producido algunas acciones; este hecho es confirmado por Doménech que habla de una concentración de doscientas a trescientas personas ante el ayuntamiento ${ }^{24}$.

En el País Vasco, en Vizcaya el diario El Correo hablaba de «rotundo fracaso» y consideraba que la vida había transcurrido «por los cauces de la más absoluta normalidad 25 ; un documento de los militantes comunistas de la provincia reconocía que no habían tenido lugar acciones de envergadura, no obstante afirmaba la existencia de un importante movimiento de trabajo lento que había hecho que en la semana de 5 al 10 la producción en las fábricas fuese muy reducida, sin poder confirmarlo hablaba de algunas acciones en la Babcok Wilcox pero sin llegar a la huelga; también mencionaba que «muchos bilbaínos no tomaron autobuses ni trolebuses, aunque la acción de boicot no fuese visible» 26 . En Guipúzcoa Mundo Obrero informaba la existencia de un paro casi total en Hernani y parcial en Andoain, Beasain y Pasajes, en San Sebastián mencionaba que en la fábrica de frigoríficos Ramón Vizcaíno los obreros se habían lanzado a la huelga y la Policía Armada había intervenido con violencia, en Contadores, Luzuriaga y las cocheras de autobuses y trolebuses situadas en Ategorrieta, según este periódico, los obreros se resistían a entrar a trabajar y solo lo hicieron coaccionados por la Policía, mientras en Cementos Recla hubo un paro parcial y los obreros entraron a trabajar más tarde ${ }^{27}$.

22 PALOMERO, D.: Ios trabajadores de ENASA durante el franquismo. Barcelona, Sirius edicions, 1996, p.104.

${ }^{23}$ La jornada en Barcelona ha sido un fracaso, mayo de 1958, Archivo Histórico del Partido Comunista de España (AHPCE), Nacionalidades, Cataluña, Jac. 997.

${ }^{24}$ DOMĖNECH SAMPERE, X.: Quan el carrer va a deixar de ser seu. Moviment obrer, societat civil y canvi polític. Sabadell (1966-1976). Barcelona, Publicacions de l' Abadia de Montserrat, 2002, p.51.

${ }_{25}$ El Correo Español-El Pueblo Vasco, 6 de mayo de 1958.

${ }^{26}$ Sobre la Jornada en Vizcaya, mayo de 1958, AHPCE, Nacionalidades Euskadi y Navarra, Jac. 392.

27 Mundo Obrero, 15-31 de mayo y 15 de junio de 1958 
En Asturias según García Piñeiro se intentó aprovechar la excitación existente por el conflicto del mes de marzo, reclamando garantías para el ejercicio de las funciones sindicales y la liberación de los trabajadores detenidos durante el conflicto; en opinión de este historiador la jornada no tuvo el menor eco, principalmente por la clara vinculación que se establecía entre la convocatoria y el PCE que se había visto sometido a un fuerte campaña de desprestigio periodístico a raíz de la anterior huelga ${ }^{28}$. Mundo Obrero habla de bastantes paros parciales en la construcción, sector que parece ser el menos afectado por las detenciones que habían seguido al movimiento huelguístico de marzo, y de trabajo lento, mientras en fábricas importantes no se habían hecho horas extraordinarias. Respecto a los mineros este periódico reconoce que se trabajo, aunque afirma que muchos mineros no habían acudido al trabajo con «uno u otro pretexto» 29 .

Lo ocurrido ese día en Valencia ha suscitado un cierto debate entre los historiadores Joan-Lluis Soler e Ismael Saz recogiendo fuentes del PCE hablan de un éxito relativo con paros en diversas obras de construcción, en la hidroeléctrica y en el Puerto de Valencia y otros de corta duración en Macosa y Elcano, paro en Yutera Española, huelga general en Alcoy y bajos rendimientos en Altos Hornos y en el ferrocarril de Sierra Menera en el Puerto de Sagundo ${ }^{30}$; Ramiro Reig cuestiona estos datos de estos autores y considera la jornada como un fracaso ${ }^{31}$, Gómez Roda analiza las obras anteriores y considera la repercusión de la jornada como prácticamente nula aunque admite un cierto boicot a los transportes y el trabajo lento en algunas empresas ${ }^{32}$; sin duda la repercusión de la jornada en Valencia fue muy reducida, pero esta ciudad no había participado en los grandes movimientos huelguísticos que habían tenido lugar en el bienio 1956-1958 y en ese contesto podría valorarse los resultados de la jornada, y posiblemente así lo hicieron los comunistas valencianos, como un paso adelante. En el caso del debate sobre Alcoy no deja de ser significativo que Mundo Obrero hable de abstención de ir al mercado por parte de la inmensa mayoría de las mujeres, circulación de los autobuses casi vacíos hasta la una de la tarde, momentos en que el trafico estaba prácticamente suspendido y no se veía a nadie por las calles, boicot a la compra de la prensa y paros de dos a cuatro horas en las principales fábricas, paros y trabajo lento en la construcción y solo se informa de un paro total durante todo el día en la principal obra de la ciudad ${ }^{33}$.

28 GARCÍA PIÑEIRO, R.: Los mineros asturianos bajo el franquismo (1937-1962). Madrid, Fundación 1. ${ }^{\circ}$ de Mayo, 1990, p.310.

29 Mundo Obrero, 15 de junio de 1958.

30 SOLER, J.L. y SAZ, I.: «De lo Rat Penat al Congreso de Castellón: Las Comisiones Obreras en el País Valenciano", en D. Ruiz (dir.): Historia de Comisiones Obreras (1958-1988). Madrid, Siglo Veintiuno de España Editores, S.A., 1993, pp. 293-294.

31 REIG R.: «Huvo un antes y un después de Asturias (Valencia, 1959-1964)» en R. Vega (coord) op. cit. pp.353 y 357-358.

32 GOMÉZ RODA, J. A.: Comisiones Obreras y la represión franquista. Valencia 1958-1972. Valencia, Universitad de Valencia, 2004, pp 64-65.

33 Mundo Obrero, 15 de junio de 1958. 
En Andalucía Eloísa Baena y Teresa Ortega hablan de «mínima respuesta por parte de los trabajadores andaluces, que se habrá traducido en el caso de Granada en el paro de varios obreros del sector de la construcción, como construcciones Soler y los trabajadores de la obra del pantano de Cubillas, el cese de actividades por parte de varios jornaleros del municipio de Pinos Puente y de los remolacheros de Macarena ${ }^{34}$, Mundo Obrero señala, además de lo anterior la existencia de fábricas y talleres donde "se trabajó muy lentamente" y habla de boicot a los tranvías y a la prensa ${ }^{35}$. En el caso de Sevilla estas autoras consideran que la respuesta fue nula ${ }^{36}$; sin embargo Mundo Obrero para la capital hispalense habla de un boicot generalizado al transporte, que alcanzaría a un $90 \%$, lo mismo que en los mercados y tiendas, de estacionamientos de trabajadores a la puerta de las empresas preguntando si se hacia huelga y que «Raro fue el lugar donde se entró al trabajo a la hora habitual o donde se efectuara el trabajo al ritmo acostumbrado" y de un cierto nivel de paro en el sector de la construcción; mientras que en los Astilleros, SACA, donde según Encarna Ruiz días antes había aparecido una hoja llamando a sumarse al conflicto y firmada por los enlaces, aunque con posterioridad la mitad de ellos accedió a firmar un aviso desvinculándose del llamamiento ${ }^{37}$, según Mundo Obrero en esta empresa se habría producido un paro de dos horas en protesta por la detención de varios enlaces, y en la misma, como en otras fábricas, ese día los trabajadores se negaron a hacer horas extraordinarias, además se informaba que la mayoría de las empresas no habían denunciado las faltas al trabajo de sus empleados; así mismo se hablaba de la ausencia al trabajo de un gran número de campesinos en diversas localidades de la provincia ${ }^{38}$. Foweraker señala que los trabajadores del astillero de Cádiz habían hecho huelga ese día ${ }^{39}$.

Que en algunos casos Mundo Obrero magnificaba la respuesta a la jornada podemos verlo en el caso de Cantabria en donde el periódico habla de paros parciales en varias fábricas y talleres de la capital y trabajo lento en otros lugares ${ }^{40}$; $\sin$ embargo documentos del partido ${ }^{41}$, aclara que estos paros fueron muy pequeños, coincide con la anterior fuente en señalar que la principal acción de la región se había sido el paro en la SNIACE de Torrelavega, pero mientras Mundo Obrero afirma que el paro duró toda la jornada los documentos internos del PCE aclaran que el paro duró desde las ocho a las once de la mañana; en lo que coinciden en señalar ambas fuentes es que a consecuencia del mismo fueron detenidos o despedidos

${ }^{34}$ BAENA LUQUE, E. y ORTEGA LÓPEZ, T. M.: «1962, «el mayo andaluz». Andalucía ante las huelgas mineras de Asturias», en R. Vega (coord.) op. cit. p.149.

35 Mundo Obrero, 30 de junio de 1958.

36 BAENA LUQUE, E. y ORTEGA LÓPEZ, T.M. op. cit. p. 149.

${ }^{37}$ RUIZ GALACHO, E.: Historia de las Comisiones Obreras de Sevilla. Primera parte: De la dictadura franquista a la legalización. Sevilla, Universidad de Sevilla, 2002, p.19.

38 Mundo Obrero, 15-30 de mayo, 30 de junio y 15 de julio de 1958.

39 FOWERAKER, J.: La democracia española. Los verdaderos artífices de la democracia en España. Madrid, Arias Montalvo Editores, S.L., 1990, p.157.

40 Mundo Obrero, 15 de junio de 1958.

41 Información de Santander sobre la jornada y La jornada y la huelga de la...AHPCE, Nacionalidades: Asturias y Cantabria, Jac 24 y 25 respectivamente. 
numerosos trabajadores, concretamente según la segunda de las fuentes hubo alrededor de 200 despedidos y 30 detenciones, los primeros serían readmitidos, con cinco excepciones.

En otros muchos lugares de España Mundo Obrero hablara de boicot a los transportes y de trabajo a ritmo lento, no deja de ser curioso como este medio informativo apuntara éxitos muy variados a la jornada, así en el caso de Soria, además de paros y trabajo lento en la construcción señalará como manifestación de oposición a la dictadura que en la tarde de ese día «la mayor parte de los vecinos se vistieron de domingo y salieron a pasear como si fuera un día de fiesta ${ }^{\$ 2}$.

\section{VALORACIÓN DE LOS RESULTADOS}

Como podemos ver la participación de las masas en la jornada fue bastante modesta lo que ha llevado a los historiadores a ver este movimiento, al igual que otros de parecida naturaleza que vendrían con posterioridad como un fracaso; no obstante algunos dirigentes comunistas la considerarían años después como un éxito contraponiéndola la Huelga Nacional Pacifica que tendría lugar el año siguiente; es el caso de Sixto Agudo aunque se ve obligado a reconocer que esta solo fue «una manifestación de la vanguardia de los elementos más conscientes y no un patrimonio de las conciencias colectivas de las amplias masas de la población» ${ }^{43}$. Tras la misma Mundo Obrero hizo una declaración entusiasta sobre su resultado calificándola como «el primer movimiento político de carácter nacional, organizado, contra el franquismo" y considerándola como el principio de una nueva fase en la lucha contra la dictadura ${ }^{44}$; quizás los comunistas españoles vieron en ella una especie de revolución de 1905 a la española.

En esta reivindicación del éxito de la jornada el diario comunista va a encontrar argumentos en la propia prensa del régimen, pese a que esta había proclamado el fracaso de intento del 5 de mayo, hablando de que el día había transcurrido en completa normalidad ${ }^{45}$; pero en los meses anteriores había calificado los diferentes procesos huelguísticos como resultado de una maniobra comunista ${ }^{46}$, Mundo Obrero va a dar un giro al argumento y a considerar que la jornada no sólo debía contemplarse en los sucesos ocurridos ese día sino que los procesos huelguísticos que había ocurrido desde su convocatoria en septiembre del año anterior debían de considerarse dentro de ella ${ }^{47}$, de esta manera los mineros asturianos «habían dado comienzo a la Jornada», con su huelga del mes de marzo ${ }^{48}$.

42 Mundo Obrero, 15 de julio de 1958.

43 AGUDO «BLANCO», S.: Memorias (La tenaz y dolorosa lucha por la libertad, 1939-1962). Huesca, Instituto de Estudios Altoaragoneses-Diputación de Huesca, 1991, pp. 346-347.

44 Mundo Obrero 15 de mayo de 1958.

45 Veasé por ejemplo Pueblo 5 de mayo de 1958.

46 Ídem 31 de marzo de 1958, para el caso de Asturias.

47 «ESPAÑA SE HA PRONUNCIADO», Mundo Obrero, 15 de junio de 1958.

48 Mundo Obrero, 15 de junio de 1958 
Prácticamente ningún historiador admite este argumento y ven en ella un fracaso; Carme Molinero y Pere Ysàs consideran que este resultado y el de la de la convocatoria del año siguiente mostraban los errores de percepción de los dirigentes de las organizaciones obreras antifranquistas, en este caso del PCE, así como que la mayoría de los trabajadores no secundaban convocatorias lanzadas por directorios políticos, desvinculadas de reivindicaciones concretas sobre sus condiciones de vida y trabajo, de más que dudoso éxito y de elevadísima peligrosidad. A ello hay que añadir que la represión desencadenada por las huelgas anteriores había desarticulado los núcleos obreros más combativos y atemorizado al resto de los trabajadores ${ }^{49}$.

Este último punto es señalado también por los comunistas vizcaínos que consideran que la dislocación de la organización había impedido que el partido «jugase el papel que le correspondía ${ }^{50}$. En este aspecto Sixto Agudo reconoce, aunque se refiera a la huelga del año siguiente, que la organización del partido era débil y no estaba en condiciones de coordinar a los distintos sectores que hubieran hecho posible una huelga general ${ }^{51}$, si esto era así en 1959 no creo que un año antes la situación fuera muy diferente.

Otro hecho agravaba esta debilidad, como se ha visto la dirección del PCE hablaba en su convocatoria de acciones «según las condiciones concretas de cada lugar», ¿pero que ocurría en los lugares, que debemos suponer serían la mayoría en que no hubiera nadie que coordinara el proceso y que determinara que hacer?, hay que suponer que en estos casos lo que se debía hacer quedó al libre criterio de los posibles militantes de base sin mucha coordinación, salvo quizás en algunas fábricas, lo que era lo menos indicado para un proceso de ese tipo.

Así el uso del trabajo lento que parece ser, según Mundo Obrero, una actitud muy generalizada ese día; en opinión de Alfredo López Serrano era el método de lucha obrera que menos comprometía a la militancia por ser el más difícil de probar, y por tanto con mayores posibilidades de escapar al castigo ${ }^{52}$, por tanto podía resultar eficaz cuando se trataba de conseguir reivindicaciones alterando la producción, pero en este no era el caso sino precisamente de todo lo contrario había que demostrar que se había seguido una convocatoria de huelga, por tanto su uso resultaba contradictorio con el resultado propuesto.

Otro tanto puede decirse de los paros durante una parte de la jornada, al no estar prefijada de antemano tanto los convocantes como los que los combatían podían sentirse victoriosos, los primeros por el paro en si, como reflejan los diferentes números de Mundo Obrero, pero también los encargados de reprimir el movi-

49 MOLINERO, C. e YSÀS, P. op. cit. p.42.

50 Sobre la Jornada en Vizcaya......

${ }^{51}$ AGUDO «BLANCO», S. op. cit. p.353.

52 LÓPEZ SERRANO, A.: «La actividad sindical en el franquismo 81939-19759» en D. Ruiz y J. Babiano (ed.): Los trabajadores de la construcción en el Madrid del siglo XX. Madrid, Akal-Fundación $1 .^{\circ}$ de Mayo, 1993, p.133. 
miento por haber acabado con él y, como refleja en solucionado que tantas veces aparece en el ya citado informe de la Delegación Provincial del Sindicato Vertical en Madrid.

Pero junto a posibles errores organizativos que expliquen este fracaso hay que tener presentes otros grandes factores que vana hacer posible la continuación de la dictadura; pese a la existencia de los conflictos laborales ya señalados, y la incorporación al movimiento obrero de nuevas fuerzas, como los católicos, que se unían a sus componentes tradicionales, los conflictos seguían siendo obra de una minoría; el miedo a la represión, la falta de liderazgo y organización o la tendencia a la pasividad eran patentes entre los trabajadores en los años cincuenta ${ }^{53}$.

Podía parecer ingenuo que el llamamiento del PCE para participar en la jornada se dirigiera también a los miembros de las Fuerzas Armadas y de las Fuerzas de Seguridad del Estado, no obstante dado que se trataba de lograr un cambio político pacífico era necesario que estos sectores, si no tomaban una actitud activa en el derrocamiento del régimen, al menos guardasen una actitud pasiva que posibilitase la evolución, sin duda el ejemplo más cercano en el tiempo era la instauración de la II República Española, donde los componentes de estos cuerpos habían aceptado, de mayor o menor gana, el cambio de régimen en el país. Pero desde luego este no era un asunto fácil, puede que muchos miembros de las Fuerzas de Seguridad, mostrasen una cierta comprensión hacia las reivindicaciones de los obreros en huelga, cuando comprendían que estas eran de naturaleza laboral y no política; puede que algunos miembros de las Fuerzas Armadas discreparan, incluso fuertemente, de algunas decisiones de la política gubernamental; pero de ahí pensar que estos sectores estuvieran dispuestos a implicarse en la aventura de un cambio de régimen había una gran distancia. Otro tanto puede decirse de las fuerzas socio-económicas que apoyaban al franquismo.

Además entre la España de 1931 y la de 1958 había grandes diferencias, entre ellas la existencia de una guerra civil que pese a posibles intenciones reconciliatorias seguía pesando en la mentalidad de los españoles, pero sobre todo había una diferencia importante, en el primero de estos años las fuerzas que se oponían a la monarquía, en su inmensa mayoría, habían llegado a un acuerdo, el Pacto de San Sebastián, para ofrecer a los españoles una alternativa al régimen imperante y tenían organismos comunes para coordinarse. En la España de 1958 este hecho no se daba, las fuerzas de la oposición se hallaban divididas y eran incapaces de coordinarse para ofrecer una alternativa común al franquismo, como se ha podido ver en esta comunicación a la vez que preparaba su Jornada de Reconciliación Nacional el PCE había propuesto el logro de algún tipo de pacto tanto con las fuerzas de la oposición tradicional como con las nuevas fuerzas que estaban surgiendo en el país, pero éste no se dio y la huelga sería casi completamente obra de los

53 PEREZ, J. A.: Los años del acero. La transformación del mundo laboral en el área industrial del Gran Bilbao (1958-1977). Trabajadores, convenios y conflictos colectivos. Madrid, Editorial Biblioteca Nueva, S. L., 2001, pp. 238-239. 
comunistas, e incluso contaría con la oposición de muchos de los grupos opuestos al franquismo.

En tales condiciones era prácticamente imposible que las instituciones y los grupos económicos en las que se apoyaba el franquismo se decidieran a abandonarle y a embarcarse en la aventura de un cambio de régimen con un resultado muy incierto, este hecho era percibido por los dirigentes comunistas y así Mundo Obrero, al comentar los resultados de la Jornada la calificaría como «ensayo para un gran movimiento nacional contra la dictadura, cuya realización exige la unidad de los partidos y grupos antifranquistas» ${ }^{54}$.

Sin esa unidad la jornada se quedaba en la jornada del PCE; este hecho va a ser usado por la prensa del régimen así Pueblo al analizar las causas del fracaso de la misma, en un artículo en el que reconocía la existencia de un cierto descontento popular, citaba los dos elementos que habían provocado este fracaso: su inspiración comunista y el miedo popular a la inestabilidad y la violencia política ${ }^{55}$.

Tampoco hay que olvidar los factores externos, en un Mundo que se encontraba dividido en dos grandes bloques liderados por Estados Unidos y la Unión Soviética, España se encontraba dentro del territorio que correspondía al primero; para esta superpotencia la España de Franco caracterizada por su anticomunismo era una garantía mucho mayor que una oposición como la señalada y en la que un partido comunista parecía querer imponer su liderazgo.

De esta manera, pese a que el régimen se encontraba atravesando una fuerte crisis, los intentos del PCE para derribarlo van a fracasar y el franquismo va a poder imponer sus propias soluciones y sobrevivir hasta la muerte del dictador.

54 Mundo Obrero 15 de mayo de 1958.

55 «ESTAS SON NUESTRAS OPINIONES», Pueblo 5 de mayo de 1958. 